\title{
Estatuto do Idoso \\ A Dignidade d Pessoa Humana e sua Proteção Social no Município De Macaé
}

\begin{abstract}
David Augusto Fernandes
Pós-doutor em Democracia e Direitos Humanos pela Universidade de Coimbra/Portugal. Doutor e mestre em Direito. Bacharel em Ciências Jurídicas e Sociais pela Universidade Federal do Rio de Janeiro (1988) e graduado em Engenharia Mecânica pela Fundação Técnico Educacional Souza Marques (1987). Professor-adjunto da Universidade Federal Fluminense (Departamento de Direito do Instituto de Ciências da Sociedade de Macaé). Docente dos cursos de Especialização em Gestão Pública, Gestão Pública Municipal e Gestão em Saúde Pública, na modalidade de Ensino a Distância, ofertados pela Universidade Federal Fluminense por meio de Consórcio Cederj e da Universidade Aberta do Brasil (UAB). Orcid: <http://orcid.org/0000-0001-7259-3827>. fernandes.ddaf@gmail.com
\end{abstract}

\section{Bruna de Azevedo Brandão}

Aluna do 10 o período do Curso de Direito da Universidade Federal Fluminense/Campus do Instituto de Ciências da Sociedade/Departamento de Direito de Macaé. CV: http://lattes.cnpq.br/3816242553642656.

fernandes.ddaf@gmail.com

O presente artigo objetiva dar visibilidade à situação de potencial violência sofrida pelo idoso no município de Macaé e abordar o impacto social e cultural na população da cidade. A importância do presente trabalho justifica-se pela necessidade de viabilizar as medidas tomadas pelo poder público a fim de sanar as infrações, minimizando sua incidência e oferecendo meios de qualidade de vida à pessoa idosa, bem como contribuindo para educar o jovem para que no futuro não seja maltratado quando estiver na condição de idoso. A metodologia para alcançar este objetivo compreende um levantamento inicial dos processos referentes ao tema junto a Justiça Estadual com atuação em Macaé-RJ, abrangendo o período de 2012 a 2015. Na sequência será desenvolvida pesquisa na Secretaria de Desenvolvimento Social, Direitos Humanos e Acessibilidade da prefeitura de Macaé, para determinar as políticas públicas direcionadas a este segmento da população e sua eficácia, à luz do Estatuto do Idoso. Pretende-se verificar se as vigentes medidas de conscientização e assistência aos idosos minimiza a violência sofrida por eles, assim como investigar até que ponto a população tem conhecimento de que o desrespeito ao idoso pode configurar crime.

Palavras-chave: Estatuto do Idoso. Violência ao idoso. Município de Macaé.

STATUTE OF THE ELDERLY: THE DIGNITY OF THE HUMAN BEING AND ITS SOCIAL PROTECTION IN THE MUNICIPALITY OF MACAE

\section{ABSTRACT}

This article aims to give visibility to the situation of potential violence suffered by the elderly in the municipality of Macae and to address the social and cultural impact of the population of the city. The importance of the present study is justified by the need to make feasible the measures taken by the Public Power in order to remedy the infractions, minimizing their incidence and offering quality of life to the elderly, as well as contributing to educate the youth so that in the future be abused when you are elderly. The methodology to achieve this objective comprises an initial survey of the processes related to the subject at the State Court with a performance in Macae-RJ, covering the period from 2012 to 2015. Next, a research will be developed with the Secretariat for Social Development, Human Rights and Accessibility of the Municipality of Macae, to determine public policies aimed at this layer of society and its effectiveness, in light of the Statute of the Elderly. The intention is to verify if the current measures of awareness and assistance to the elderly minimize the violence suffered by them, as well as investigate to what extent the population has clarification that the disrespect to the elderly can constitute crime.

Keywords: Statute of the Elderly. Violence against the elderly. Municipality of Macae.

SUMÁRIO

1 Introdução. 2 A Dignidade da Pessoa Humana e a Eficácia dos Direitos Fundamentais. 2.1 Mínimo Existencial. 3 Evolução do Direito do Idoso na Legislação Brasileira. 4 O Idoso e seu Espaço na Família. 5 Violência Contra a Pessoa Idosa. 5.1 O Microcosmo da Cidade de Macaé. 5.2 Programas Sociais no Município de Macaé. 6 Conclusão. 7 Referências. 


\section{Introdução}

A presente pesquisa, inserida na seara do Direito Penal e da dignidade da pessoa humana, aborda a situação dos idosos, que por vezes vivem subjugados pelo Estado, a sociedade e sua família, constituindo uma população cuja longevidade é fruto do avanço tecnológico, especialmente nas ciências voltadas para a preservação da saúde, ao possibilitar aos seres humanos uma existência mais prolongada no ambiente social. Por outro lado, o prolongamento da vida acarretou outros problemas para esta camada populacional, sendo mais frequente a violência doméstica. Tal condição levou a que fossem consideradas como tema deste artigo as políticas públicas integradas de promoção ao bem-estar social, com o objetivo de investigar a efetividade da garantia dos direitos fundamentais destinados aos idosos, tendo como diapasão a Constituição Federal de 1988 e a Lei no 10.741/2003. De semelhante importância para o presente enfoque, examinam-se, mediante pesquisa de campo, as relações entre a configuração familiar e as condições de saúde física e psicológica dos idosos e sua satisfação com os relacionamentos familiares na cidade de Macaé-RJ.

É salutar considerar que a cidade-foco desta pesquisa, é o microcosmo a ser analisado, mas não pode ser considerado um paradigma para a sociedade brasileira como um todo, onde existem idosos como nas demais cidades do nosso país, os quais possuem um atendimento diverso ao que ocorre na cidade objeto de nossa pesquisa.

A pessoa idosa, objeto principal da pesquisa, é vítima constante de desrespeito e diversos tipos de violência, como a física e a psicológica e, por essa razão, apesar de já ter direitos garantidos na Constituição Federal, passou a receber amparo especial por meio do Estatuto do Idoso que, se for seguido de forma correta, garantirá qualidade de vida para a população idosa, cada vez mais crescente no Brasil.

No país, apesar do aumento da expectativa de vida da população, elevando o número de pessoas idosas, a maturidade tem sido considerada muitas vezes como etapa de degradação do ser humano, pois o idoso passa a ser visto como improdutivo, dependente e incapaz. O ancião é percebido como alguém impossibilitado de desenvolver seu potencial humano, tornando-se oneroso para a família e um fardo para a sociedade, uma vez que o aumento da expectativa de vida eleva gastos com previdência social e saúde.

Diante destas postulações, o presente artigo trata dos fatores a serem considerados para se manter condignamente a vida do idoso em sociedade. Inicialmente abordam-se a dignidade da pessoa humana e a eficácia dos direitos fundamentais, fatores que devem existir no cotidiano do ser humano, mas que se tornam mais necessário na terceira idade. $O$ encerramento deste tópico foi feito abordando o mínimo existencial.

Na sequência enfocam-se os direitos do idoso no ordenamento pátrio, passando pelas Constituições e as normas infraconstitucionais, até chegar ao Estatuto do Idoso. A partir daí verifica-se a convivência do idoso no ambiente familiar em comparação com os princípios dessas medidas protetivas.

O tópico seguinte trata da violência contra o idoso, descrevendo-se o resultado da pesquisa voltada para esta população e respectivos programas sociais no âmbito do município de Macaé. São investigados os recursos disponibilizados pelos órgãos públicos, assim como 
os meios utilizados para garantia de vida digna à pessoa idosa, pois o Estado está configurado naqueles dispositivos legais como agente garantidor dos direitos e garantias fundamentais. Encerra-se o trabalho com as conclusões retiradas da pesquisa em comento.

Nesse sentido, o trabalho procura cumprir a finalidade de averiguar o desempenho da família, da sociedade e do Estado, assim como o êxito dos programas sociais adotados pelo município de Macaé, bem como a aplicabilidade dos direitos e garantias do referido grupo dispostos no texto normativo.

\section{A Dignidade da Pessoa Humana e a Eficácia dos Direitos Fundamentais}

Apesar de ser uma expressão constantemente utilizada em diversos meios e centros de discussão, a dignidade da pessoa humana, por diversas vezes, não é observada em sua essencialidade. Nessa perspectiva, evidencia-se a frequência do uso dessa expressão nas últimas décadas, ao ser citada em inúmeros documentos internacionais, como a Declaração Universal de Direitos Humanos, em leis, em decisões judiciais e em Constituições de diversos países, inclusive no Brasil. Não obstante, mesmo com o uso corriqueiro nos meios sociais, acadêmicos e judiciais, o questionamento acerca dessa expressão envolve a necessidade de aprofundamento do conceito, a fim de se obter um resultado coerente com a amplitude de seu significado.

A dignidade é algo inerente ao homem, da qual não há como se desvencilhar, pois decorre da própria condição do ser humano. Assim sendo, é de abrangência universal, perpassando culturas, etnias e crenças. Isso posto, insta salientar que não há como o indivíduo deixar de possuir dignidade, mesmo sendo sua pretensão, pois é algo independente da autonomia da vontade (grifos deste artigo). Então, não há que se referir a variações de proporcionalidade da dignidade da pessoa humana, tendo por base condutas tomadas ou não pelo indivíduo, pois todos os homens a têm em similar proporção.

Consoante ao explanado, nota-se que esse conceito amplo, ao envolver os aspectos já citados, não deve ser confundido com o considerado como direito fundamental. Conforme Luís Roberto Barroso,

[...] a dignidade da pessoa humana é parte do conteúdo dos direitos materialmente fundamentais, mas não se confunde com qualquer deles. Nem tampouco é a dignidade um direito fundamental em si, ponderável com os demais. Justamente ao contrário, ela é o parâmetro da ponderação, em caso de concorrência entre direitos fundamentais, como se explorará mais adiante (2010, p. 14).

É interessante também a afirmativa de Ingo Wolfgang Sarlet ao ressaltar a conexão entre os dois termos, a saber:

A dignidade da pessoa humana, na condição de valor fundamental atrai o conteúdo de todos os direitos fundamentais, exige e pressupõe o reconhecimento e proteção dos direitos fundamentais de todas as dimensões. Assim, sem que se reconheçam à pessoa humana os direitos fundamentais que lhes são inerentes, em verdade estar-se-á negando-Ihe a própria dignidade (2003, p. 88-89). 
Em observância a esse diapasão, percebe-se que a dignidade da pessoa humana tem relação intrínseca com os direitos fundamentais, apesar de não se misturarem. Os direitos fundamentais vêm como maneira de integralizar a concretização do que a dignidade da pessoa humana traz em seu encalço, de forma a incluir no ordenamento jurídico normas que tratem desses direitos. Aqui é válido ressaltar que os direitos fundamentais, diferentemente do caráter universal fundamentado pela dignidade da pessoa humana, tendem a ser estabelecidos de formas variadas de acordo com o contexto histórico-social da nação sobre a qual se inserem.

Tratando de ambos os termos, releva observar seu papel ao fazerem parte e estarem elencados no ordenamento jurídico, pois possibilitam maior efetivação. Os direitos fundamentais não se confundem com os direitos humanos, pois aqueles são direitos devidamente positivados no ordenamento de determinado Estado, sendo logicamente limitados no tempo e espaço, enquanto estes são direitos reconhecidos ao homem, mas não necessariamente positivados em uma Constituição, visando à validade além de uma nação.

Nesse sentido, vale ressaltar que os direitos fundamentais devem ser aplicados nas relações, a fim de solucionar conflitos, não os resolvendo de maneira direta, pois não possuem tal força. A preservação dos direitos fundamentais garante proteção dos indivíduos contra possíveis ações que os atinjam. Assim, nota-se que a eficácia dos direitos fundamentais possui íntima conexão com o resguardo da dignidade da pessoa humana ao tratar dos direitos existenciais, e serve como norteador para os demais.

Maria Berenice Dias (2007, p. 62) enuncia que "a dignidade da pessoa humana funciona como fórmula originária que dá origem a todos os outros existentes". Essa sua capacidade insere-se, segundo a autora, no fato de este ser essencial para a possibilidade de existência dos demais. Tem-se: o princípio da dignidade humana é o mais universal de todos os princípios. É um macroprincípio do qual se irradiam todos os demais: liberdade, autonomia privada, cidadania, igualdade, uma coleção de princípios éticos (DIAS, 2007, p. 62 - grifos deste trabalho).

Assim, os direitos fundamentais possuem a função de servir como norteadores para a interpretação das normas que não são constitucionais, com as decisões do Judiciário devendo buscar sempre a preservação desses direitos, visando a assegurar ao homem tanto os direitos que Ihe são inerentes e atemporais quanto os que sofrem restrições e limitações.

\subsection{Mínimo Existencial}

Entende Ricardo Lobo Torres (1999, p. 138) que o mínimo existencial (ME) é "um direito às condições mínimas de existência humana digna que não pode ser objeto de intervenção do Estado e que ainda exige prestações estatais positivas". O mínimo existencial, primariamente, está direcionado à liberdade e à democracia, não devendo ficar restrito a este direcionamento, posto que as condições básicas de vida devam ser asseguradas de forma a atender aqueles que delas necessitam. 


\section{Democracia}

A pobreza absoluta relaciona-se também com o $\mathrm{ME}$, constituindo dever do Estado combatê-la, diversamente da pobreza relativa, que está vinculada à situação econômica do país em determinado momento social (TORRES, 2009, p. 21) ${ }^{1}$.

Acrescente-se que o ME é um direito pré-constitucional, não positivado na Carta Magna, mas embutido no artigo 3으, inciso III, como um dos objetivos da República Federativa do Brasil, qual seja: a erradicação da pobreza e da marginalização. Também pode ser encontrado no corpo da CF/1988, no artigo 6으, pois se aproxima dos direitos fundamentais sociais, estando, igualmente, registrado em emendas constitucionais (14/1996, 29/2000, 31/2000, $41 / 2003,42 / 2003,45 / 2003$ e 53/2007), vinculando as receitas públicas às despesas com educação, saúde e pobreza (TORRES, 2009, p. 7).

Na esfera infraconstitucional há a referência ao mínimo existencial no artigo 10 da Lei Orgânica da Assistência Social (Lei no 8.742, de 7 de dezembro de 1993), que salienta o seguinte:

A Assistência Social, direito do cidadão e dever do Estado, é política de Seguridade Social não contributiva, que provê os mínimos sociais, realizada através de um conjunto integrado de ações de iniciativa pública e da sociedade, para garantir o atendimento às necessidades básicas (PLANALTO, 1998).

$\mathrm{Na}$ esfera internacional verifica-se registro ao ME, conforme assinalado nos artigos 15 e 16 da Declaração Universal dos Direitos Humanos (DUDH).

Verifica-se que a Declaração sobre o Direito ao Desenvolvimento, aprovada pela Resolução n. 41/128 da Assembleia Geral das Nações Unidas, de 4 de dezembro de 1986, reconheceu o seguinte:

O desenvolvimento é um processo econômico, social, cultural e político abrangente, que visa ao constante incremento do bem-estar de toda a população e de todos os indivíduos com base em sua participação ativa, livre e significativa no desenvolvimento e na distribuição justa dos benefícios daí resultantes. ${ }^{2}$

A Carta Europeia de Direitos Humanos estampa inúmeros princípios referentes ao ME, entre eles o artigo 34.3: "A fim de lutar contra a exclusão social e a pobreza, a União reconhece e respeita o direito a uma ajuda social e a um auxílio à moradia" (TORRES, 2009, p. 12).

$\mathrm{O}$ ME abrange qualquer direito, ainda que não fundamental, considerado em sua dimensão essencial, inalienável e existencial. Não se pode afirmar que existe um elenco fechado de direitos ou prestações componentes do ME, visto que as necessidades básicas resultam por vezes da evolução social no plano social ou cultural, podendo aqui ser incluída a vida digna sem pobreza (SARMENTO, 2016, p. 219-220), entretanto é possível incluir a liberdade neste rol, como requisito do ME.

\footnotetext{
A pobreza absoluta ou miséria é aquela que desafia o status positivus libertatis, gerando obrigatoriedade da prestação pública por parte do Estado e constituindo direito público subjetivo para o cidadão. De outra forma, a pobreza relativa carece da interpositio legislatoris na alocação de verbas necessárias à entrega de prestações vinculadas aos direitos sociais.

2 O artigo 10 prevê o seguinte: "O direito ao desenvolvimento é um direito humano inalienável em virtude do qual toda pessoa humana e todos os povos estão habilitados a participar do desenvolvimento econômico, social, cultural e político, a ele contribuir e dele desfrutar, no qual todos os direitos humanos e liberdades fundamentais possam ser plenamente realizados".
} 
Com o Pacto Internacional sobre Direitos Econômicos, Sociais e Culturais (CAMARA..., 1992) houve a ampliação e o aperfeiçoamento do catálogo dos direitos constantes na Declaração de 1948, conforme descrito no artigo 2 :

Cada Estado-Parte do presente Pacto compromete-se a adotar medidas, tanto por espaço próprio como pela assistência e cooperação internacionais, principalmente nos planos econômico e técnico, até o máximo de seus recursos disponíveis, que visem a assegurar, progressivamente, por todos os meios apropriados, o pleno exercício dos direitos reconhecidos no presente Pacto, incluindo, em particular, a adoção de medidas legislativas.

\section{Evolução do Direito do Idoso na Legislação Brasileira}

É notável a preocupação da atual legislação brasileira em relação aos meios de proteção e garantia da cidadania dos idosos na sociedade. Visando a propiciar uma boa qualidade de vida durante a longevidade, o Estatuto do Idoso traz medidas protetivas, que tratam não somente da violência física, mas também da moral.

A Constituição de 1934 foi a primeira a tratar de maneira clara sobre o direito dos anciãos $^{3}$ no ordenamento jurídico brasileiro. As Constituições que se seguiram mantiveram a timidez no trato do idoso. ${ }^{4}$ A Constituição de 1988 veio apresentar nova perspectiva no trato do idoso, conforme pode ser percebido pelo conteúdo do artigo 1으, III, elevando tal princípio ao nível de formador da estrutura social, objetivando a promoção da justiça social e dos direitos humanos.

No entendimento de Ingo Wolfgang Sarlet (2012, p. 234), a dignidade da pessoa humana seria uma espécie de limite a não ser ultrapassado por quaisquer restrições ou garantias, conforme se observa no disposto:

[...] o reduto intangível de cada indivíduo e, neste sentido, a última fronteira contra quaisquer ingerências externas. Tal não significa, contudo, a impossibilidade de que se estabeleçam restrições aos direitos e garantias fundamentais, mas que as restrições efetivadas não ultrapassem o limite intangível imposto pela dignidade da pessoa humana.

O artigo 3ำ da Constituição Federal de 1988 também prevê, como um dos objetivos fundamentais da República, a promoção do bem-estar de todos os indivíduos, sem que haja qualquer forma de discriminação, o que a diferencia das demais no tocante ao aspecto social apreciado. A inserção dos idosos não se deu apenas de forma ampla e geral, havendo disposição específica de que os filhos maiores devem amparar e ajudar os pais na velhice, carência ou enfermidade. $O$ texto constitucional acrescenta que o Estado e a sociedade têm o dever de amparar os anciãos, demonstrando o efetivo avanço legislativo em relação à inserção participativa dos idosos, bem como seu bem-estar, dignidade e, sobretudo, real cidadania, sugerindo que os programas de amparo aos idosos terão execução preferencialmente em seus lares.

\footnotetext{
3 Em seu artigo 121, ao fato de que a legislação trabalhista tinha o dever de observar a instituição da previdência em prol da velhice e que a diferença salarial que advinha de divergência de idades era proibida, não se preocupando em momento algum em tratar do aspecto social dos anciãos.

4 A Constituição de 1934 destacava a garantia de seguros de velhice na alínea "m" do artigo 137; a Constituição de 1946 proibia a diferença salarial em razão da idade e fez referência a características previdenciárias em prol dos idosos em seu artigo 157, incisos II e XVI; já as Constituições de 1967 e 1969 nada trouxeram de novo sobre o idoso, apenas referindo-se ao aspecto previdenciário, como consta em seu artigo 158, inciso XVI.
} 


\section{Humanos e}

Democracia

Tal fato revela uma preocupação do legislador constituinte também em relação ao núcleo familiar do ancião, conduzindo a percepção de que a retirada do idoso de seu lar deve ocorrer de forma excepcional. ${ }^{5}$ Cabe complementar esta proposta com as palavras de Roberto Mendes de Freitas Júnior (2008, p. 65):

O idoso tem o direito de ser mantido em seu próprio lar, a fim de que sejam preservados sua intimidade, o direito de propriedade, a privacidade, cultura e costumes, bem como para garantir a manutenção dos laços familiares. [...]. Necessário não olvidar, porém, que o convívio familiar não pode ser imposto ao idoso capaz, devendo constituir uma opção do mesmo.

Insta ressaltar que a somatória de todos esses direitos estabelecidos constitucionalmente engloba a longevidade, que foi notoriamente objetivada pelo legislador constituinte. É válido destacar, entretanto que esse alcance foi objetivado de forma digna, com envelhecimento saudável e participativo ante a comunidade na qual o ancião venha a viver e exercer ação.

Conforme estabelecido no artigo 20 da Lei Orgânica da Assistência Social (Loas), o benefício da prestação continuada é direito apenas dos idosos que possuam 65 (sessenta e cinco) anos ou mais. Nota-se aqui a preocupação com a mantença do idoso, ressaltando mais uma vez a importância de sua dignidade. Há que se ressaltar, todavia, que a proteção trazida pela Constituição vigente pode, em alguns aspectos, vir a extrapolar a proposta inicial, como ocorre no caso do seu artigo $40, \S 1$ 으. II, ao prever o seguinte:

Art. 40. Aos servidores titulares de cargos efetivos da União, dos Estados, do Distrito Federal e dos Municípios, incluídas suas autarquias e fundações, é assegurado regime de previdência de caráter contributivo e solidário, mediante contribuição do respectivo ente público, dos servidores ativos e inativos e dos pensionistas, observados critérios que preservem o equilíbrio financeiro e atuarial e o disposto neste artigo.

$\$ 1$ O Os servidores abrangidos pelo regime de previdência de que trata este artigo serão aposentados, calculados os seus proventos a partir dos valores fixados na forma dos $\S \S$ 3으 e 17:

1 - por invalidez permanente, sendo os proventos proporcionais ao tempo de contribuição, exceto se decorrente de acidente em serviço, moléstia profissional ou doença grave, contagiosa ou incurável, na forma da lei;

II - compulsoriamente, com proventos proporcionais ao tempo de contribuição, aos 70 (setenta) anos de idade, ou aos 75 (setenta e cinco) anos de idade, na forma de lei complementar (BRASIL, 1988).

Ora, ao retirar o servidor público de determinada atividade apenas pelo fato de ter atingido certa idade, fica a impressão de que ele não possui mais capacidade de executar suas funções de maneira correta, presumindo-se deste modo sua incapacidade.

Nilson Tadeu Reis Campos Silva (2012, p. 135) relata que a tal fato se dá o nome de excrescência constitucional a erodir o fundamento republicano da dignidade da pessoa humana, contribuindo para fixar a imagem de incapacitação do idoso.

A gratuidade de locomoção nos transportes públicos, garantida no parágrafo 20 do artigo 230 da CF/1988, também demonstra a preocupação do legislador em proporcionar real integração do idoso não só com a comunidade em que vive, mas com a sociedade como um todo. 
Com este procedimento evidencia-se a notória caracterização da vulnerabilidade dos idosos, pois, com idade avançada e tratamento recebido da família, apresentam aspectos específicos para sua exclusão de atividades profissionais ou sociais, tais como doenças crônicas, por exemplo.

A Política Nacional do Idoso, estabelecida pela Lei no 8.842, de 4 de janeiro de 1994, foi a primeira legislação criada com a finalidade de dispor sobre as necessidades dos idosos. Desde sua criação tem o objetivo de legislar sobre os direitos sociais dos anciãos, a fim de garantir sua participação efetiva, integração social e autonomia durante a vida em sociedade. Este normativo visa à promoção de circunstâncias que proporcionem o envelhecimento provido de efetivo bem-estar social e qualidade de vida, mediante ações restritivas a qualquer tipo de discriminação contra os anciãos.

Salienta Rulli Neto (2003, p. 103-104) que as diretrizes dessa Política perpassam por formas de convívio do idoso que possibilitem sua integração com as outras gerações, a participação em sociedade por meio de organizações representativas, priorização do atendimento ao idoso por sua família, capacitação dos recursos humanos nas áreas de geriatria e gerontologia e na prestação de serviços, apoio e pesquisas sobre questões relativas ao envelhecimento. Verifica-se, assim, que o objetivo principal da Política Nacional do Idoso foi a consolidação dos direitos já garantidos pela Constituição Federal de 1988, de forma a evitar a violação desses direitos e proteger de forma mais incisiva o ancião em relação aos riscos sociais.

Após cinco anos de tramitação no Congresso Nacional, foi sancionado o Estatuto do Idoso (Lei no 10.741, de 1 을 de outubro de 2003), objetivando a efetiva garantia da dignidade do idoso. Trata-se, portanto, da união das normas para a proteção do idoso, trazendo o espírito da participação da sociedade como um todo enquanto fundamental para que se alcance o estabelecido. ${ }^{6}$ Os direitos tais como assistência social, habitação, amparo à saúde, cultura, esporte, previdência social, trabalho, lazer, acessibilidade e transporte estão todos elencados no Estatuto do Idoso, de forma a consolidar o estabelecido pelo legislador de maneira mais incisiva. Não obstante, deve-se atentar para a importância atribuída ao núcleo familiar como pilar na garantia dos direitos dos idosos, bem como a sociedade como um todo, no sentido de participar efetivamente das propostas, a fim de se concretizar o normativamente previsto.

Dessa forma, percebe-se que a Constituição Federal, a Política Nacional do Idoso e o Estatuto do Idoso tratam o grupo familiar como peça fundamental na garantia dos direitos do ancião. $\mathrm{E}$ tal responsabilidade não se manifesta somente nos aspectos relativos à proteção do idoso, mas também na habitação, alimentação, respeito e afetividade, fatores cuja existência no bom convívio familiar vão refletir-se na sociedade.

Ante o exposto, não há que se falar apenas da oportunidade de tais regramentos ante o número de idosos existentes, entretanto faz-se necessária a real aplicação do que é estabelecido normativamente, com a contribuição indispensável da sociedade, para que o disposto seja cumprido e se alcance lugares mais altos na concreta proteção aos direitos dos idosos.

Conforme o Estatuto, tem-se a proteção assistencial às pessoas com 60 (sessenta) anos ou mais, com o cunho garantidor de sua saúde física e mental, bem como à educação, lazer, convivência com a família e com a comunidade. Tentou-se efetivamente coibir negligências, opressão, violência, crueldade e discriminação, prevendo inclusive punições na forma da lei. 


\section{Idoso e seu Espaço na Família}

A Lei no 10.741/2003 assegura aos idosos diversos direitos em vários âmbitos, inclusive no que se refere à saúde e ao bem-estar. A senilidade traz a decrepitude como um de seus mais evidentes sinais, fato que, por si só, já seria motivo suficiente para o tratamento diferenciado desse grupo, entretanto a previsão de tratamento diferenciado e assegurado por lei não tem sido suficiente para suprir as reais necessidades de grande parcela de idosos.

O ambiente em que vive o idoso é fundamental para sua boa saúde física e mental, mas como a família tem acompanhado essa evolução e de que maneira estaria garantindo o espaço ideal dessa pessoa no seio familiar? Primeiramente, ao se falar do espaço do idoso na família, há de se levar em consideração alguns fatores que inegavelmente são determinantes neste tratamento.

A situação econômica da família é um dos principais aspectos a ser levado em conta, pois, entre outros fatores, costuma-se encontrar famílias em que a renda do idoso é primordial para o sustento e/ou manutenção do status familiar. Logo, independentemente de ser uma família pobre ou não, o idoso que recebe geralmente uma quantia considerável assume uma posição de destaque. Obviamente, no caso das famílias menos favorecidas, muitas vezes a sua contribuição torna-se fundamental, pois até mesmo o pagamento do imóvel onde moram e as despesas essenciais para o sustento familiar podem advir dos proventos do idoso.

Vale ressaltar que a participação intensiva do idoso na área financeira da família pode ter pouco a ver com o tratamento que lhe é dispensado, pois é possível encontrar o idoso que muito contribua e ainda assim viver excluído, isolado, sem poder de decisões, mas também quem seja tratado como verdadeiro chefe da família, participativo, cercado de cuidados e amor.

A velhice traz consigo inúmeros preconceitos errôneos. A fragilidade física e mental, marca da faixa etária, incute na cabeça das pessoas a ideia de que o idoso é um ser incapacitado, necessitando ser cuidado e protegido, quando na realidade ainda muito pode contribuir para a família e a sociedade. Tal aspecto tem a ver com a inversão de papéis muitas vezes constatada em várias famílias: por serem vistos como limitados em muitos aspectos, filhos e netos os tratam como filhos. É muito comum ver filhos que se tornam pais de seus pais.

Apesar de se encontrar muitos avós cuidando de netos, é pertinente observar que muitos ainda não chegaram à casa dos 60 anos, portanto não são considerados idosos segundo a legislação. É notório que o conceito de idoso vem mudando, histórica e culturalmente, na sociedade, à medida que procura se adequar às necessidades da sociedade e de seus interesses econômicos e políticos. Também é inegável que o idoso da era contemporânea necessita de uma legislação que contemple suas novas expectativas.

Conforme mencionado anteriormente, é importante reiterar que a família é um dos principais alicerces da pessoa idosa e uma base afetiva, financeira e de sua integração ao meio social. Pode funcionar de forma inclusiva ou de exclusão do idoso, a depender de como será construída essa relação. Quando a família desempenha um papel integrador, busca atender aos anseios e necessidades dos idosos, de forma a integrá-los na rotina do lar, de modo a Ihes proporcionar um convívio familiar tranquilo e harmonioso. Essa integração atua de forma 
positiva para o psicológico e bem-estar do idoso. Já quando a família o exclui ou negligencia, ele passa a sofrer física e psicologicamente por não contar com a devida assistência e, como consequência, tem sua expectativa de vida reduzida em razão do tratamento inadequado.

\section{Violência Contra A Pessoa Idosa}

Constata-se ser a realidade brasileira caracterizada pelos elevados índices de violência, de acordo com dados da Organização das Nações Unidas (ONU). O Brasil ocupa a 16a posição entre os países mais violentos do mundo. Essa violência é causada por problemas econômicos e sociais, como a desigualdade provocada pela má distribuição de renda, pelos problemas de assistência aos mais pobres, pelo alto índice de corrupção dos órgãos públicos e dos políticos, assim como pelo aumento crônico das taxas de desemprego, agravando o cometimento de ilícitos. Tal violência faz com que as camadas mais vulneráveis da população, crianças e adolescentes, mulheres e idosos, sintam tal problema de forma mais intensa.

É visível a preocupação, por parte do poder público, em tutelar direitos e garantias fundamentais aos grupos mais vulneráveis, a exemplo dos anteriormente mencionados. No grupo de vulneráveis, a violência contra o idoso é violação aos direitos fundamentais, uma das menos visíveis e mais difíceis de ser identificada, pois na maioria das vezes o próprio idoso acredita que a violência sofrida faz parte do envelhecer e não denuncia o agressor que, em grande parte dos casos, é membro da própria família (filhos, noras e genros ou netos).

Conforme estabelece o Estatuto do Idoso, a "violência contra o idoso é qualquer ação ou omissão praticada em local público ou privado que lhe cause morte, dano ou sofrimento físico ou psicológico (art. 19, § 1)”. Essa violência ocorre por diferentes motivos, entretanto é possível citar como mais relevante a degradação das relações familiares. O fato de os idosos não pertencerem a um grupo economicamente ativo e produtivo, além de sua vulnerabilidade física e psicológica, faz com que fiquem expostos a situações de dependência. É importante esclarecer que tal violência pode se dar de diferentes formas, tais como as manifestadas por Maria Cecília Minayo:

Violência física: é o uso da força física para compelir os idosos a fazerem o que não desejam, para feri-los, provocar dor, incapacidade ou morte.

Violência psicológica: corresponde a agressões verbais ou gestuais com o objetivo de aterrorizar, humilhar, restringir a liberdade ou isolar do convívio social.

Violência sexual: refere-se ao ato ou jogo sexual de caráter homo ou heterorrelacional, utilizando pessoas idosas. Esses abusos visam a obter excitação, relação sexual ou práticas eróticas por meio de aliciamento, violência física ou ameaças.

Abandono: é uma violência que se manifesta pela ausência ou deserção dos responsáveis governamentais, institucionais ou familiares de prestarem socorro a uma pessoa idosa que necessite de proteção e assistência.

Negligência: refere-se à recusa ou à omissão de cuidados devidos e necessários aos idosos por parte dos responsáveis familiares ou institucionais. É uma das formas de violência mais presentes no país. Ela se manifesta frequentemente associada a outros abusos que geram lesões e traumas físicos, emocionais e sociais, em particular para os que se encontram em situação de múltipla dependência ou incapacidade. 
Humanos

Democracia

Violência financeira ou econômica: consiste na exploração imprópria ou ilegal ou ao uso não consentido pela pessoa idosa de seus recursos financeiros e patrimoniais.

Autonegligência: diz respeito à conduta da pessoa idosa que ameaça sua própria saúde ou segurança, pela recusa de prover cuidados necessários a si mesma.

Violência medicamentosa: é administração por familiares, cuidadores e profissionais dos medicamentos prescritos, de forma indevida, aumentando, diminuindo ou excluindo os medicamentos.

Violência emocional e social: refere-se à agressão verbal crônica, incluindo palavras depreciativas que possam desrespeitar a identidade, a dignidade e a autoestima. Caracteriza-se pela falta de respeito à intimidade, falta de respeito aos desejos, negação do acesso a amizades, desatenção a necessidades sociais e de saúde (MINAYO, 2010, p. 45 - grifos deste trabalho).

É importante salientar a urgência para que se torne perceptível a violência praticada contra o idoso, pois ela apresenta contornos alarmantes na sociedade, ou seja, é um fenômeno social assustador e, na maioria das vezes, silencioso. No caso, vale lembrar que existe responsabilidade do Estado, da sociedade e da família para o enfrentamento dessa questão. O Estado, como agente garantidor, precisa promover programas de conscientização da população por meio de debates sociais, além de trabalho preventivo, para a sociedade identificar casos de violência praticada contra o idoso, além de instituir uma política voltada para a valorização da pessoa idosa, a fim de estimular uma mudança cultural na sociedade.

A família desempenha papel de extrema importância, que é o da integração e socialização do ancião para ele se sentir inserido na sociedade de forma confortável e satisfatória. Enquanto isso, a sociedade precisa entender o significado das diversas formas de violência ao idoso, para fazer uma leitura "nas entrelinhas", consistente em análise detalhada de casos específicos ocorridos todos os dias que precisam ser denunciados. A cultura do silêncio, da não intromissão nos "problemas pessoais" e familiares precisa ser extinta, pois a violência em suas diferentes formas não é "problema privado", mas um problema social grave a ser erradicado.

\subsection{O Microcosmo da Cidade de Macaé}

A pesquisa foi desenvolvida no município de Macaé, com base em amostragem que pudesse detectar, com o nível de assertividade desejado para a elaboração do presente trabalho, o conhecimento da população investigada sobre os dispositivos normativos que tutelam seus direitos, como o Estatuto do Idoso e a Constituição Federal. Foram visitados os dois asilos existentes no município, nos quais foram entrevistados 56 homens e 74 mulheres, além de um grupo de idosos, composto por 162 mulheres e 42 homens, que são assistidos pela Secretaria de Desenvolvimento Social, Direitos Humanos e Acessibilidade, em seus diversos programas direcionados a esta camada da população.

No que se refere aos conhecimentos da população-alvo sobre os dispositivos legais de seu interesse foi observado o seguinte: $32 \%$ dos entrevistados que participam de programas sociais conhecem ou já ouviram falar do Estatuto do Idoso e da Constituição Federal; $13 \%$ dos idosos das Instituições de Longa Permanência (asilos) conhecem ou já ouviram falar do Estatuto do Idoso e da Constituição Federal. 
O nível de escolaridade dos entrevistados, conforme comprovam as amostras, é variável, não havendo muita alteração entre os dois grupos estudados. O perfil dos participantes das atividades promovidas pela Secretaria de Desenvolvimento Social, Direitos Humanos e Acessibilidade apresenta que 20\% têm Ensino Médio completo, 60\% têm Ensino Fundamental e $20 \%$ são analfabetos. Já no grupo dos idosos residentes em Instituições de Longa Permanência, as porcentagens são de: $10 \%$ no Ensino Médio completo; $70 \%$ no Ensino Fundamental e $20 \%$ são analfabetos.

Em relação ao estado civil dos entrevistados frequentadores dos programas de bem-estar social, é possível depreender o seguinte: $40 \%$ são casados e $60 \%$ são viúvos. Já entre os idosos residentes em Instituições de Longa Permanência é possível observar que $23 \%$ são casados, $24 \%$ são viúvos, $46 \%$ são solteiros e $7 \%$ divorciados.

Dos idosos que participam dos cursos e oficinas promovidos pela Secretaria de Desenvolvimento Social, Direitos Humanos e Acessibilidade, apenas $20 \%$ apresentam relatos de violência. Já no grupo de idosos que vivem em Instituições de Longa Permanência, o número de relatos de violência sobe para $90 \%$. Torna-se necessário observar que a referida violência, nesse caso específico, foi praticada anos atrás, durante o casamento, sendo caracterizada como violência doméstica por parte do(a) companheiro(a) agressor(a). Os dados da violência variam nos dois grupos, podendo-se observar que os idosos residentes em Instituições de Longa Permanência sofreram reiterados e diferentes tipos de violência, enquanto que o grupo dos idosos dos programas sociais sofreu violência pontual, doméstica.

Em pesquisa realizada no Judiciário do município de Macaé, foi possível verificar que muitas denúncias anônimas são feitas por meio do telefone Disque 100. Constata-se, entretanto, que os números não representam a realidade, pois grande parte dos casos não é denunciada, levando à existência de uma cifra negra da criminalidade ${ }^{7}$ nesta espécie de crime e, entre os casos denunciados, muitos são feitos de forma leviana, por vingança pessoal, dificultando assim o trabalho do Judiciário.

\subsection{Programas Sociais no Município de Macaé}

Sabe-se que as políticas públicas direcionadas aos cidadãos de baixa renda constituem importante fundamento na sociedade e, com relação à população idosa, tal preceito não foge à regra, devendo ser cada vez mais fomentadas e discutidas, a fim de que eles tenham seus direitos resguardados.

Nesse diapasão, ao se colocarem percepção o Estatuto do Idoso como uma verdadeira junção de itens a serem observados e seguidos para que o ancião vivesse de forma digna e prolongada, é necessário constatar se o Estatuto tem suas normas adotadas como parâmetro para o tratamento do idoso na cidade de Macaé, que é o locus da presente pesquisa. Ao se

Definida como todos os crimes que não chegam ao conhecimento policial, seja praticado por pessoas do alto escalão contra o meio ambiente, como também aqueles que até chegam ao conhecimento das autoridades e são registrados, porém não chegam até o processo ou ação penal. 
Humanos

Democracia

consultar a legislação macaense, ${ }^{8}$ é possível verificar a existência de diversas leis que envolvem os idosos e visam a frisar ainda mais a segurança dos direitos já existentes na esfera federal. Ademais, há a preocupação do município em relação ao desenvolvimento de programas que amparem essa demanda, de forma mais incisiva. ${ }^{9}$

Torna-se importante destacar que o principal público atendido é carente, tendo o município o objetivo de oferecer auxílio à família no sentido de, com o suporte necessário para cuidar do idoso em seu lar, ele não seja posto em asilo ou venha a sofrer maus-tratos.

Em relação ao exercício da comunicação, há o projeto “Oficina de Memória: Oficinas de Leitura e Escrita e de Habilidades Comunicativas", voltado para o estímulo da independência comunicativa oral do idoso, além de proporcionar a diminuição das dificuldades de comunicação e memória que tendem a surgir com o avançar da idade.

O município em estudo também mostra preocupação em orientar os idosos, a fim de eles virem procurar a Administração sempre que tiverem denúncias ou reivindicações a serem feitas nos casos de violência ou violação aos seus, por meio do "Projeto Ligue Idoso". Outro canal de comunicação também oferecido à população idosa em situação de risco é o "Plantão Assistencial ao Idoso", que presta atendimento psicológico e jurídico, além de serviço social, para orientá-lo e encaminhá-lo ao órgão competente ante o caso concreto.

\section{Conclusão}

Ao longo desta pesquisa ficou evidente que o Brasil possui uma legislação moderna voltada ao idoso, à medida que busca proteger e garantir os direitos fundamentais, o mínimo existencial necessário a todo e qualquer indivíduo.

A análise do Estatuto do Idoso leva a uma reflexão interessante e pontual, que versa sobre sua funcionalidade, pois, ao verificar os dados apontados na pesquisa, fica nítido o desconhecimento da maior parte da população idosa entrevistada sobre a lei especial que tutela seus direitos. Da mesma forma, é importante a maior divulgação por parte do poder público da citada legislação, para que, por meio do conhecimento, a sociedade tenha como exigir determinados direitos inerentes aos idosos e que, por desconhecimento, muitas vezes acabam "perdidos".

\footnotetext{
No que respeita à legislação municipal, a Lei no 2.310, de 24 de dezembro de 2002, surgiu como forma de priorizar o atendimento de idosos, gestantes e portadores de deficiência física, obrigando os entes administrativos, bem como as autarquias, a realizarem a inclusão de um setor que atenda a essa demanda de forma adequada.

A Lei no 2.482/02 de 23 de abril de 2004 celebra o convênio entre a prefeitura e a Liga Beneficente São João Batista de Macaé - Casa do Idoso, pelo qual o município oferece efetivo suporte para a mantença do asilo de forma digna e justa.

Há também outros diplomas legislativos municipais que objetivam cuidar dos direitos dos idosos, tais como: a Lei no 4.095/2015, de 21 de janeiro de 2015, que trata da instituição do Dia Municipal do Cuidador de Idoso, fazendo referência a este importante profissional; a Lei no 4.139/2015, 10 de dezembro de 2015, que visa a garantir a entrada gratuita de idosos em eventos de cunho cultural; e a Lei Ordinária no 4.342/2017, de 3 de maio de 2017, que assegura que todos os assentos existentes nos terminais rodoviários, ônibus do transporte público e pontos de parada sejam destinados preferencialmente aos idosos, deficientes, gestantes e lactantes.

9 No mês de setembro de 2016, como forma de integrar as gerações, a prefeitura promoveu o lançamento de uma cartilha infantil que trata sobre o Estatuto do Idoso de forma lúdica, para ensinar às crianças sobre as normas do Regimento.

$\mathrm{O}$ atendimento às demandas dos anciãos tem sido priorizado pela Secretaria Municipal de Desenvolvimento Social e Direitos Humanos e Acessibilidade, que oferece diversos projetos voltados exclusivamente para os idosos. Estes projetos são desenvolvidos por meio do "Programa Valorização do Idoso", que assiste mais de 3.500 (três mil e quinhentos) idosos, preocupando-se sempre em observar as necessidades de cada um.
} 
Em relação ao cumprimento do Estatuto do Idoso no município de Macaé, é importante informar que a cidade dispõe de diversas políticas públicas voltadas a essa população, promovendo a integração dos idosos e permitindo que continuem ativos e envelheçam com qualidade. O município possui um setor específico em sua administração pública, com a atribuição de realizar constantes pesquisas para identificar as necessidades e vontades da população, buscando mediante esse contato melhorar dia após dia a qualidade de vida de seus habitantes.

É válido informar que os índices de violência praticados contra a pessoa idosa não representam uma realidade do município, mas uma realidade do Brasil, que enxerga o idoso como figura improdutiva, a ser marginalizada pela sociedade.

Conclui-se que, para haver uma visão mais humanitária da velhice na cultura brasileira, é necessária a desconstrução dos padrões culturais atualmente enraizados, na perspectiva errônea de considerar o idoso uma pessoa improdutiva e inútil. Para o idoso reencontrar seu lugar ativo no meio social é de extrema importância haver discussões cujo tema principal seja a compreensão da velhice apenas como mais uma etapa cumprida na vida social, um caminho natural, pelo qual a maioria das pessoas passará, afinal "somos sempre o velho ou o jovem de alguém".

\section{Referências}

BARROSO, Luís Roberto. A dignidade da pessoa humana no Direito Constitucional contemporâneo: natureza jurídica, conteúdos mínimos e critérios de aplicação. Versão provisória para debate público. Mimeografado, dez. 2010.

BRASIL. Constituição da República Federativa do Brasil. Brasília, DF: Senado Federal, 1988.

CÂMARA. Decreto no 591, de 6 de julho de 1992. Brasília, Diário Oficial da União de 7 de julho de 1992. Disponível em: <http://www2.camara.leg.br/legin/fed/decret/1992/decreto-591-6-julho-1992-449000-publicacaooriginal-1-pe.html>. Acesso em: 10 set. 2017.

DIAS, Maria Berenice. Manual de Direito das Famílias. 8. ed. rev. atual. ampl. São Paulo: Editora Revista dos Tribunais, 2007.

FREITAS JUNIOR, Roberto Mendes de. Direitos e garantias do idoso: doutrina, jurisprudência e legislação. Belo Horizonte: Del Rey, 2008.

MINAYO, Maria Cecília. Violência contra idosos: o avesso do respeito à experiência e à sabedoria. 2. ed. Brasília, DF: Secretaria Especial dos Direitos Humanos, [2010?].

PLANALTO. Lei no 8.742, de 7 de dezembro de 1993. Diário Oficial da União, Brasília, DF, 8 dez. 1998. Disponível em: <http://www.planalto.gov.br/ccivil_03/leis/L8742.htm>. Acesso em: 10 set. 2017.

ROCHA, Eduardo Gonçalves. Estatuto do Idoso: um avanço legal. Revista da UFG, Goiânia, v. 5, n. 2, dez. 2003. Disponível em: <http://www.proec.ufg.br>. Acesso em: 27 jul. 2017.

RULLI NETO, Antônio. Proteção legal do idoso no Brasil: universalização da cidadania. São Paulo: Fiuza, 2003.

SANTA CATARINA (Estado). Secretaria de Estado da Assistência Social, Trabalho e Habitação. Conselho Estadual do Idoso. Direito do idoso: conhecer para defender. Florianópolis: loesc, 2014.

SÃO PAULO (Estado). Secretaria de Saúde. Coordenação de Desenvolvimento de Programas e Políticas de Saúde (Codepps). Violência doméstica contra a pessoa idosa: orientações gerais. São Paulo: SMS, 2007.

SARLET, Ingo Wolfgang. A eficácia dos direitos fundamentais. 3. ed. Porto Alegre: Livraria do Advogado, 2003.

. Dignidade da pessoa humana e direitos fundamentais na Constituição Federal de 1988. 9. ed. Porto Alegre: Livraria do Advogado, 2012.

SARMENTO, Daniel. Dignidade da pessoa humana: conteúdo, trajetórias e metodologia. Belo Horizonte: Fórum, 2016.

SILVA, Nilson Tadeu Reis Campos. Direito do idoso: tutela jurídica constitucional. Curitiba: Juruá, 2012.

TORRES, Ricardo Lobo. O direito ao mínimo existencial. Rio de Janeiro: Renovar, 2009.

Tratado de Direito Constitucional Financeiro e Tributário: os direitos humanos e a tributação - imunidades e isonomia. Rio de Janeiro: Renovar, 1999. V. 3. 